\title{
A CATEGORIA NOME E SEU ASPECTO NOME PRÓPRIO: UMA APROXIMAÇÃO ENTRE ABORDAGENS TRADICIONAIS E A VISÃO DERRIDIANA
}

\author{
Renato Cardoso Corgosinho
}

Doutorando - Programa de Pós-Graduação em Estudos Linguísticos / PUC Minas

\begin{abstract}
RESUMO
As categorias nome e nome próprio despertaram reflexões ao longo dos anos, referentes a sentido e referência. Com base nesse argumento, o presente texto pretende traçar uma aproximação crítica, no plano das abordagens sobre nome e nome próprio, entre o terreno filosófico (cerne paradigmático e contemporâneo, mormente, em Derrida) e o linguístico.
\end{abstract}

\section{PALAVRAS-CHAVE}

Linguagem, filosofia, nome, sentido, referência

Compreender derridianamente o nome próprio, ao mesmo tempo que simula desconstruir algo do alicerce filosófico que pensou por séculos língua e linguagem, acoberta, um tanto em paradoxo, inúmeras convergências com a tradição, no sentido de recuperá-la, redimensioná-la ou recondicioná-la ao locus vivificus do nome, da tradução do nome ou de sua refundição no símbolo babélico.

Com efeito, o complexo-nome desprende-se de um conteúdo sensível que se buscou imprimir, formatado, a partir de uma apreensão de mundo, na expressão verbal que "diz" o objeto acoplado à realidade. O binômio linguagem/realidade mescla-se a um construto terminológico contemporâneo, a saber: sentido/referente. Nessa perspectiva, o referente, mais que um objeto que se reconhece por uma materialidade primitiva, especifica-se, isola-se pela nomeação (asserção descritiva ou nome próprio), e se distingue de outro objeto pela concepção que dele se tem, traduzida pela linguagem. Da ideia de referente, depreende-se a de sentido, que tem a ver com o modo como os referentes são percebidos ou conhecidos. 
De acordo com Platão, ${ }^{1}$ o nome é um dos elementos fundamentais na compreensão da coisa. Em par com proposição e imagem comportaria intrinsecamente um caráter de mutabilidade (se se considera que esses elementos são sempre uma representação da coisa). Por conseguinte, a linguagem, imersa numa instabilidade mudadora, seria incapaz de traduzir a verdadeira essência do objeto, que é fixa. De sorte que o nome, por sua natureza imagética, patenteia imperfeição para designar o que com ele se pretende, podendo comportar grau maior ou menor de similitude com a coisa. Seu uso viabiliza-se, contudo, por um pacto, por uma convenção - linguística porque social - a possibilitar sua aceitação para representar os objetos.

Em Aristóteles o nome é tido por símbolo, e, como tal, não atinge a substância das coisas. O que ocorreria, na verdade, é que não conseguimos produzir a dissociação entre nome e objeto, pois ambos possuiriam, ilusoriamente, um vínculo necessário simbólico - a atrelar em nós a impressão de que a sorte do nome seja a mesma da coisa. Todavia, de acordo com o estagirita, “entre nomes e objetos não há semelhança total; os nomes são em número limitado, bem como a pluralidade das definições, mas as coisas são em número infinito”. ${ }^{2}$

Derrida $^{3}$ filtra a reflexão que encetaram os gregos, e, pelo viés da chamada Teologia Negativa, que parece constituir-se em uma experiência da “desconstrução” a perseguir “a possibilidade do impossível” dos nomes de Deus, infere que a linguagem, no suporte de qualquer idioma, não dá conta desse impossível, não dispõe de significantes possíveis para esse impossível, é limitada de imagens e representações para uma realidade transcendente. Assim,

[De Deus] nada é dito que afirme (...) salvo o nome, que não nomeia nada que afirme, nem mesmo uma divindade, nada cujo ocultamento desloque qualquer frase que tente comparar-se a ele. "Deus" "é" o nome desse desmoronamento sem fundo, dessa desertificação sem fim da linguagem. ${ }^{4}$

Segundo os autores de Port-Royal, em sua Grammaire générale et raisonnée, ${ }^{5}$ as ideias das coisas são singulares ou gerais, o que teria gerado a necessidade de se

\footnotetext{
${ }^{1}$ PLATÃO. Carta VII.

${ }^{2}$ ARISTÓTELES. Organon VI, 1: elencos sofísticos, p. 62.

${ }^{3}$ DERRIDA. Salvo o nome.

${ }^{4}$ DERRIDA. Salvo o nome, p. 36, 37.

${ }^{5}$ Obra originalmente publicada em 1660.
} 
nomearem convencionalmente os objetos. ${ }^{6}$ De modo que os nomes equivaleriam a palavras que "significam os objetos dos pensamentos"7 de maneira singular ou geral. Daí a distinção entre nomes próprios e nomes comuns. Tanto uma categoria como a outra representam os chamados nomes substantivos, uma vez que significam a coisa em si (substância), que é aquilo que subsiste por si mesmo. ${ }^{8}$ Por seu turno, essas categorias subsistem por si mesmas no discurso. Se ocorrer de um nome próprio se referir a vários objetos, uma vez que fora adotado por muitos indivíduos, perderia sua característica de singularidade, e o caráter de próprio só poderia ser readquirido quando viesse o nome conjugado a outros que o determinariam. ${ }^{9}$

A leitura derridiana aponta para o fato de que poderia parecer, em princípio, que o nome próprio vincula-se intrinsecamente ao objeto por ele nomeado, que o princípio da nomeação seria a base mesma da linguagem e que haveria um ideal de nomeação própria, “eventualmente da verdade mesma”. ${ }^{10}$ Porém, provoca-nos o filósofo afirmando categoricamente que nome próprio não existe, o que não deixa de ser um reconhecimento do referido aspecto convencional ou simbólico dos nomes. Ou seja, "para que houvesse um nome verdadeiramente próprio, seria preciso que houvesse senão um único nome próprio, que não seria então nem mesmo um nome, mas pura convocação do outro puro, vocativo absoluto". ${ }^{11}$ Se se podem conferir vários nomes a um indivíduo que, num aqui-agora, “pensa e é”, esses nomes já não são mais “propriamente próprios, [e] é a exatidão dessa verdade que vincula a língua a um instante fundador”. ${ }^{12} \mathrm{Na}$ verdade, o nome que se diz próprio nada mais seria que o desdobramento ou uma apropriação do comum a insinuar-se na língua, a partir de uma relação entre linguagem e mundo ou experiência, entre espaço do legível e espaço do visível. Isto equivale a dizer que pensamento e linguagem, diferentemente do senso comum, não se encobrem.

\footnotetext{
${ }^{6}$ Aqui, a reflexão platônica de que os objetos precederiam aos nomes. Estes seriam imitação da ideia das coisas.

${ }^{7}$ ARNOLD; LANCELOT. Gramática de Port Royal, p. 31.

${ }^{8}$ Correspondente à noção aristotélica de substância.

${ }^{9}$ Retoma-se, por essa visão, o argumento aristotélico de que não seria possível negar que uma única definição ou um mesmo nome possa ser relacionado a várias coisas.

${ }^{10}$ BENNINGTON. Jacques Derrida, p. 80.

${ }^{11}$ BENNINGTON. Jacques Derrida, p. 80, 81.

12 BENNINGTON. Jacques Derrida, p. 82.
} 
Frege, ${ }^{13}$ por sua clássica objeção a que haja entre significado/sentido e referência identificação perfeita, estabelece critérios para que um nome seja próprio. Primeiramente, deve estar ligado a um único objeto (objeto singular). Não obstante, a designação de um objeto singular pode ser feita também através de várias palavras ou sinais, também chamados pelo autor de nomes próprios. Todavia, relativamente ao significado das expressões designativas de um objeto particular, o ponto de vista fregeano desvela um problema: se palavras ou expressões são identificadas com um único objeto, elas comportariam o mesmo significado, pelo motivo de que são coreferentes, mas não seriam necessariamente sinônimas. Poder-se-ia inferir então que: 1) há a possibilidade de que um objeto singular tenha mais de um significado/sentido; 2) o significado/sentido nem sempre garante a referência, o que quer dizer que, no caso de nomes fictícios, a referência não é identificável; 3) as representações (imagens internas, processos psicológicos) variam de indivíduo para indivíduo, o que importa dizer que a representação do objeto não pode ser confundida com sua referência ou com seu significado/sentido. Dessa forma, o sentido seria aquilo que possibilita a relação do nome próprio com o mundo, ou seja, através do sentido, estabelecer-se-ia a referência do nome próprio.

Derrida $^{14}$ procura aduzir que tudo é referência, e que coincide esta, portanto, com os limites da linguagem. Por ser limite, a referência é sempre inadequada e, por conseguinte, o referente nem sempre é indispensável. A linguagem mesma é reveladora de tal inadequação e de que todo saber, a partir da experiência da relação com o mundo e, obviamente, com a referência, é insuficiente ou enfraquecido. Cria-se assim, por desacomodação referencial, um abismo “necessário" e dicotômico entre revelação/conhecimento e segredo/transcendência. De sorte que, por exemplo, relativamente aos nomes de Deus, todas as palavras que se dirigem a ele nomeiam-no “fazem referência àquilo mesmo que o nome supõe nomear para além dele mesmo, o nomeável além do nome, o nomeável inomeável”. ${ }^{15}$

Se para Frege ${ }^{16}$ os nomes próprios comportam sentido, porquanto, “referindo-se” a objetos singulares em um conjunto equiparar-se-iam pela função a certas expressões

\footnotetext{
${ }^{13}$ FREGE. Lógica e filosofia da linguagem.

${ }^{14}$ DERRIDA. Salvo o nome.

${ }^{15}$ DERRIDA. Salvo o nome, p. 41.

${ }^{16}$ FREGE. Lógica e filosofia da linguagem.
} 
linguísticas capazes de informar sobre propriedades intrínsecas aos objetos nomeados, ${ }^{17}$ tal posição não é defendida unanimemente. Certos autores ${ }^{18}$ optaram por seguir a tese de J. S. Mill, segundo a qual, nos termos de Mari, “sendo [o nome próprio] mera etiqueta pregada às coisas, assegura referência, mas o faz sem se constituir em um modo de apresentação do objeto, logo, sem que tenha sentido.” ${ }^{19}$ Isto implica dizer que os nomes próprios não comportariam os elementos necessários para informar a respeito da natureza do objeto que designam, o que descortina ainda uma controversa questão: os nomes próprios (pessoais e de lugares) fariam parte, assim como as demais palavras, dos sistemas linguísticos particulares? Argumentos contrários se apóiam no fato de que eles não são elementos integrantes dos dicionários, se se considera, na esteira dos lexicógrafos, que sejam vazios de significação. Além disso, não haveria um princípio único que orientasse a tradução de nomes próprios de uma língua para outra. ${ }^{20}$

A tese do nome-etiqueta encontra eco nas reflexões de Derrida sobre a divindade e os nomes de Deus. Como acima expusemos, a partir dos argumentos do autor, com exceção do nome, qualquer coisa que se diga a respeito de Deus não o afirma. A afirmação do nome paradoxalmente não é uma nomeação da coisa, da divindade, da essência da divindade. O nome nada mais seria que o precípuo momento fundador de uma experiência com o transcendente. Novamente aqui, a fragilidade da referência a outorgar ao nome unicamente um status de verdade, de testemunho da coisa ("além do próprio nome”). Este, no entanto, não pode ser a coisa que ele nomeia, não revela sua essência, não pertence a quem o recebe ou a quem o dá:

Cada coisa, cada ente, você, eu, o outro, cada X, cada nome e cada nome de Deus pode se tornar o exemplo de outros $\mathrm{X}$ substituíveis. Processo de formalização absoluta. Cada outro é cada outro. Um nome de Deus, em uma língua, uma frase, uma prece, torna-se um exemplo do nome e dos nomes de Deus e em seguida dos nomes em geral. ${ }^{21}$

${ }^{17}$ Argumentos a favor da tese de Frege podem ser lidos em SEARLE. Actos de fala, p. 217, 218, citado por MARI. Aspectos da teoria da referência, p. 113.

${ }^{18}$ Cf., por exemplo, LYONS. Semântica, p. 180: "Uma das questões mais debatidas é a de saber se os nomes têm um sentido. A perspectiva filosófica mais aceita hoje em dia é que eles podem ter referência, mas não sentido, e não podem ser usados predicativamente enquanto nomes próprios. Será esta a perspectiva que adotaremos.”

${ }^{19}$ MARI. Aspectos da teoria da referência, p.112.

${ }^{20}$ GEACH. Reference and generality: an examination of some medieval and modern theories, p. 27. Citado por LYONS. Semântica, p.183.

${ }^{21}$ DERRIDA. Salvo o nome, p. 65. 
Além do que, questiona-se, no texto de 1995, se nome e nome próprio fariam parte da linguagem ou nela estariam, justamente porque esta linguagem seria reveladora constante da já referida inadequação da referência. Enfaticamente em Torres de Babel, de 2002, outro argumento para o não pertencimento, ao menos do nome próprio, como as outras palavras, a qualquer língua, seria o seu caráter perene de intraduzibilidade. Um nome próprio "não pode se inscrever propriamente na língua senão deixando-se nela (...) interpretar no seu equivalente semântico: desde esse momento ele não pode mais ser recebido como nome próprio”. ${ }^{22}$

O presente texto procurou, de forma sintética, mas com o devido rigor comparativo, destacar as principais abordagens que se desenvolveram ao longo do tempo sobre nome e nome próprio, promovendo uma aproximação necessária entre o terreno filosófico e o linguístico, com base na compreensão de que se construiu este, em muitos momentos, alicerçado por aquele. Nossa intenção principal, entretanto, foi enquadrar algo das reflexões de J. Derrida à tradição, demonstrando que o filósofo franco-argelino não deixou de nela se reafirmar, se "retraduzir", se reciclar, quando virtualmente abordou questões como a inexatidão do nome e sua incapacidade de dizer a natureza das coisas; referência; os vários nomes possíveis de um mesmo referente; nome-etiqueta; a ausência de sentido dos nomes próprios e de seu consequente caráter de intraduzibilidade.

\begin{abstract}
The categories name and proper name had motivated reflections throughout the years on meaning and reference. On the basis of this argument, the present text intends to trace a critical approach regarding name and proper name, between the philosophical field (traditional and contemporary kernel, mainly, in Derrida) and the linguistic field.
\end{abstract}

\title{
KEYWORDS
}

Language, philosophy, name, meaning, reference

\footnotetext{
${ }^{22}$ DERRIDA. Torres de Babel, p. 22.
} 


\section{REFERÊNCIAS}

ARISTÓTELES. Organon VI: elencos sofísticos. Trad. Pinharanda Gomes. In: Os pensadores. São Paulo: Ed. Nova Cultural/Guimarães Editores, 1996, p. 61-110.

ARNAULD; LANCELOT. Gramática de Port-Royal. Trad. Bruno Fregni Basseo; Henrique Graciano Muracho. São Paulo: Martins Fontes, 1992.

BENNINGTON, Geoffrey. Jacques Derrida. Trad. Anamaria Skinner. Rio de Janeiro: Jorge Zahar Ed., 1996.

DERRIDA, Jacques. Torres de Babel. Trad. Junia Barreto. Belo Horizonte: Editora UFMG, 2002.

DERRIDA, Jacques. Salvo o nome. Trad. Nícia Adan Bonatti. Campinas: Papirus Editora, 1995.

FREGE, Gottlob. Lógica e filosofia da linguagem. Trad. Paulo Alcoforado. São Paulo: Cultrix/Edusp, 1978.

GEACH, Peter Thomas. Reference and Generality: an examination of some medieval and modern theories. London: Cornell University Press/Oxford University Press, 1962.

LYONS, John. Semântica. Trad. Wanda Ramos. Lisboa: Editorial Presença/Martins Fontes, 1980. v. I.

MARI, Hugo. Aspectos da teoria da referência. Revista de Psicologia Plural, Belo Horizonte, ano XII, n. 18, p. 93-117, 2003.

PLATÃO. Carta VII. Trad. José Trindade Santos e Juvino Maia Jr. Rio de Janeiro: Edições Loyola/PUC RJ, 2008.

SEARLE, John R. Actos de fala. Trad. Carlos Vogt. Coimbra: Almedina, 1981. 